\title{
Acaricidal Activity of Phenolic Crude Extract from Artocapus lakoocha Leaves against Cattle Tick Rhipicephalus (Boophilus) microplus
}

\author{
Wilasinee Srisanyong ${ }^{1 *}$, Dechawut Bunyaluk ${ }^{2}$, Piyarat Srinontong ${ }^{3}$ and Setthakit Chitsanoor ${ }^{4}$ \\ ${ }^{1}$ Department of Veterinary Technology, Faculty of Agricultural Technology, Kalasin University, Muang, Kalasin, \\ Thailand, 46000; ${ }^{2}$ Department of Science and Mathematics, Faculty of Science and Health Technology, Kalasin \\ University, Muang, Kalasin, Thailand, 46000; ${ }^{3}$ Bioveterinary Research Unit, Faculty of Veterinary Sciences, \\ Mahasarakham University, Muang, Maha sarakham Thailand, 44000; ${ }^{4}$ Department of Pathology, Faculty of Veterinary \\ Medicine, Mahanakorn University of Technology, Bangkok, Thailand, 10530 \\ *Corresponding author: am_bios@hotmail.com
}

\begin{abstract}
Article History: 21-292 Received: 10-Mar-21 $\quad$ Revised: 6-May-21 $\quad$ Accepted: 14-May-21
\section{ABSTRACT}

Cattle ticks and tick-borne diseases (TBDs) are well known for their harmful effects to cattle health. The problem of TBDs has been ranked high in terms of their adverse impact on the livelihood of poor farming communities in developing countries including Thailand. The aim of this research was to evaluate the efficacy of phenolic compounds of crude acetone extract and crude ethanol extract from Artocapus lakoocha leaves in the elimination of the cattle ticks which were tested in the form of crude extract at the concentration of 400, 800 and $1600 \mu \mathrm{g} / \mathrm{ml}$. From the record of mortality rate within 48 hours and propagation index within 15 days, it was found that the extract at the concentration of $1600 \mu \mathrm{g} / \mathrm{ml}$ had the best efficacy to eliminate cattle ticks when compared to control group and other concentrations $(\mathrm{P}<0.05)$. It was also discovered that the mortality rate of ticks was $72 \%$. Moreover, index of egg laying, and inhibition percentage were equal to 0.14 and 49 , respectively. The negative control group adding with polyethylene glycol (PEG, Phenolic inhibitors) had mortality rate of cattle ticks at $0 \%$ and median of toxic concentration (Lethal Concentration 50: $\mathrm{LC}_{50}$ ) of phenolic crude extract was $1050 \mu \mathrm{g} / \mathrm{ml}$. Thus, the phenolic crude extract from Atrocapus lakoocha leaves was effective in getting rid of cattle ticks, this approach could be further developed as the effective method for controlling and eliminating ticks in the form of products such as shampoo and tick spray for cattle or other animals.
\end{abstract}

Key words: Artocapus lakoocha leaves, Phenolic, Crude Extract, Rhipicephalus (Boophilus) microplus. (2)21 IJVS - All Rights Reserved

\section{INTRODUCTION}

Ticks are hematophagous ectoparasites which cause major problems in the development of Thai livestock especially cattle farming. Cattle ticks are regarded as the most relevant vectors of disease-causing pathogens in domestic and wild cattle, leading to reduced growth and milk production, paralysis, toxicosis, and transmission of tick-borne diseases (TBDs) that reduce production or cause mortality (Kemal et al. 2020). Moreover, ticks can also be a carrier of diseases to human, farmer, veterinary, animal husbandman or people involved in Thai livestock field. Therefore, the problems from cattle ticks lead to the loss of the livestock product value which plays an important role in Thailand economy. For this reason, in recent years, Thailand's animal husbandry industry has increased the import of synthetic chemicals for utilizing in the elimination of external parasites such as ticks, fleas, lice, leprosy flea and other insect diseases which can cause economic losses, negative effects on consumer health and the environment. For cattle farming, synthetic insecticides in the group of organophosphate and chlorinated hydrocarbon are popularly used to get rid of cattle tick (Ponce-Vélez and de la Lanza-Espino 2019), which can be harmful to cattle, farmers and also cause environment pollution. Furthermore, their continuous use has led to the development of acaricide resistance in ticks (Adakal et al. 2013). These factors are motivating the researchers to search the alternative ways for the effective control of ticks; therefore, many researchers have been investigating the compounds from plant extracts for their acaricidal potential (Castro et al. 2014; Veeramani et al. 2014; Adenubi et al. 2016; Marchesini et al. 2018).

Cite This Article as: Srisanyong W, Bunyaluk D, Srinontong P and Chitsanoor S, 2021. Acaricidal activity of phenolic crude extract from Artocapus lakoocha leaves against cattle tick Rhipicephalus (Boophilus) microplus. International Journal of Veterinary Science 10(4): 307-311. https://doi.org/10.47278/journal.ijvs/2021.063 
Artocapus lakoocha is royal sacred plant of Kalasin Province classified as perennial plant having the properties of erect stem, rough outer bark, seeping rubber in cracked area, monocotyledon, oval-pointed leaf tip, concave leaf base and hairy leaflet (Diaz et al. 2015; Nesa et al. 2015). Farmers prefer to use various parts of $A$. lakoocha, including core, root, bark, wood, etc as feeding ingredient to cattle. However, the leave parts are commonly destroyed by burning or using as food for raising cattle and buffaloes that have not been made much value-added. Consequently, it is interesting to find the utilization pattern of A. lakoocha leaves as the crude extracts with acaricidal properties, as well as other plant leaves extracted for use in tick control. According to previous findings, plant extracts have been proven as the promising alternative source for farmers who need to use the plant extracts in order to minimize the use of synthetic acaricides for arthropod control in their organic cattle farming resulting in lower environmental contamination, slower development of resistance and lower toxicity to animal and human (Chungsamarnyart et al. 1992; Castro et al. 1997). Currently, there is no information of using the extracts derived from A. lakoocha leaves as biological control agents against ticks. Therefore, we realized that the leaves of this plant could be a good source of phenolic compounds that are effective against ticks. This study aims to evaluate the efficacy and find optimal concentration of phenolic extract from A. lakoocha leaves for the removal of cattle ticks. Based on our findings, further research can be conducted to develop the phenolic extract from A. lakoocha leaves to be a product such as shampoo or tick spray for getting rid of ticks in cattle and buffalo.

\section{MATERIALS AND METHODS}

\section{Study Period and Location}

This study was conducted for 12 months (January to December 2020) at Faculty of Agricultural Technology, Kalasin University, Thailand.

\section{Plant Materials and Phenolic Extraction}

Leaves of A. lakoocha were collected from the Faculty of Agricultural Technology, Kalasin University, Kalasin province, Thailand in May 2020. The collected plants were identified as A. lakoocha by the Division of Biology, the Department of Science and Mathematics, the Faculty of Science and Health Technology, Kalasin University. The collected leaves were air-dried for two days and then placed in hot air oven method with the temperature of $70^{\circ} \mathrm{C}$ for 2 hours, subsequently ground into coarse powder before extraction of phenolic compounds. Afterwards, 150 grams of the obtained coarse powder were phenolic extracted with a mixture of $60 \%$ acetone and $80 \%$ ethyl alcohol at $1: 1$ in ratio and then incubated at $70^{\circ} \mathrm{C}$ for 5 hours in Erlenmeyer flask. The solution was filtered through Whatman No. 1 paper and stored in air-tight bottles at $4^{\circ} \mathrm{C}$ for further experiments (Santos et al. 2012).

\section{Determination of Phenolic Concentration}

The phenolic concentration was measured by using Folin Ciocalteu reagent adapted from the method of Slinkard and Singleton (1977). The standard solution was gallic acid mixed with $0.02 \mathrm{ml}$ sample substances (concentration level: $0.125,0.25,0.5,1.0$ and $2.0 \mathrm{mg} / \mathrm{ml}$ ), $1.55 \mathrm{ml}$ distilled water and $0.1 \mathrm{ml}$ Folin Ciocalteu reagent. Then it was left for 5 minutes, filled with $2 \%$ sodium carbonate $(0.3 \mathrm{ml})$ and mixed them together. After that, the mixed substance was left for 2 hours. The light wave absorbance at $765 \mathrm{~nm}$ was measured with UV-visspectrophotometer machine. The sample substance was repeatedly tested for 3 times. The phenolic concentrations of A. lakoocha leaf extracts were measured in the microgram form of gallic acid equivalents, which was calculated from Linear regression equation of standard curve of gallic acid graph.

\section{Ticks Collection and Identification}

The engorged adult females $R$. (B.) microplus were collected from the naturally infested calves free from any acaricidal treatments for at least 45 days and examined under stereomicroscope to identify tick species at the Department of Veterinary Technology, the Faculty of Agriculture Technology, Kalasin University. All collected ticks were washed with distilled water, dried on an absorbent paper, and kept under room temperature and $70 \%$ relative humidity in experiment boxes. Ticks were observed for body motility and pedal reflex to determine the viability before starting an adult immersion test (AIT) (Morais et al. 2012).

Determination of the Acaricidal Activity of $A$. lakoocha Leaves Extract against $R$. (B.) microplus

The acaricidal activity of $A$. lakoocha leaf extracts against cattle ticks were determined by using AIT. One hundred and fifty engorged adult female ticks were selected from herds of cattle with no history of any conventional tick control and were subsequently divided into five groups of thirty ticks per group, which were immersed into distilled water, 400,800 and $1600 \mu \mathrm{g} / \mathrm{ml}$ of A. lakoocha leaf extract solution for 5 mins, respectively, while a negative control group was immersed into $A$. lakoocha leaf extracts with polyethylene glycol (PEG) $(38400 \mu \mathrm{g} / \mathrm{ml})$ for 5 mins. The treated ticks were then withdrawn from the tested solution, placed in separate petri dishes with moist filter paper and incubated at room temperature and $70 \%$ relative humidity to observe the acaricidal activity. The tick mortality had been monitored for 15 consecutive days after treatment, and the total laid eggs weight of live female ticks were also measured. Each group of experiments were repeated for 3 times. The mortality rate, index of egg laying and percentage inhibition of fecundity was calculated by the equations shown below.

\section{The Mortality Rates}

The mortality rates $=$ Number of dead ticks/Total number of experimental ticks) x 100

\section{Index of Egg Laying}

Index of egg laying (IE) = Weight of laid tick's eggs $(\mathrm{g}) /$ Total experimental tick's weight $(\mathrm{g})$

Percentage Inhibition of Fecundity

Percentage inhibition of fecundity (IF) $=[$ IE (Control Group) - IE(Experimental Group)] x 100 


\section{Probit Analysis}

The relationship between the concentration of the extract and tick mortality was conducted using the regression equation of Abbott's formula (Abbott 1925) and expressed as a linear graph. Lethal concentrations (LC) to kill 50\% (LC50) was calculated by Probit analysis.

\section{Statistical Analysis}

Statistical analyses were performed using SPSS software version 17. Statistical significance was determined by one-way analysis of variance (ANOVA). The Duncan multiple range test (DMRT) was used for multiple comparison. Results were considered statistically significant at $95 \%$ confidence $(\mathrm{P}<0.05)$

\section{RESULTS}

\section{Phenolic Extraction and Phenolic Substance Analysis} from A. lakoocha Leaves

From the experiment, the extracted ratio was mixed with $60 \%$ acetone by volume and $80 \%$ ethyl alcohol by volume at the ratio of $1: 1$ in the phenolic extraction from A. lakoocha leaves by using $150 \mathrm{~g}$ of A. lakoocha leaves, it showed the absorption value of phenolic compound extracted from A. lakoocha leaves (Y)0.24. nm, and it was substituted in Equation 1. The received phenolic concentration $(\mathrm{X})$ was equal to $0.54 \mathrm{mg} / \mathrm{ml}$ from Table 1 .

\section{The Acaricidal Activity of A. lakoocha Leaf Extracts against $R$. (B.) microplus}

According to the calculation of percentage of cattle tick mortality with various concentration levels of $A$. lakoocha leaf extracts $(400,800$ and $1600 \mu \mathrm{g} / \mathrm{ml})$, it was discovered that mortality rate of cattle ticks was increased depending on higher level of concentrations. When compared with the control group (distilled water), it was found that all concentrations had higher mortality than the control group that the highest mortality rate of cattle ticks was $72 \%$ with the concentration of $1600 \mu \mathrm{g} / \mathrm{ml}$ (Fig. 2).

Efficacy of Phenolic Compounds in A. lakoocha Leaf Extracts on Propagation of $R$. (B.) microplus

Table 2 shows the efficacy of A. lakoocha leaf extracts on propagation of cattle ticks within 15 days at various concentrations. It shows the propagation index was lower when compared with the control group and at the concentration of $1600 \mu \mathrm{g} / \mathrm{ml}$. The lowest index of egg laying was $0.14 \%$. It was also observed that the inhibited reproduction was higher when the extract concentration was increased. At the concentration of $1600 \mu \mathrm{g} / \mathrm{ml}$, the highest percentage of propagation inhibition was 49 . Moreover, each experimental group was statistically significant $(\mathrm{P}<0.05)$ which suggested that $A$. lakoocha leaves extract has efficacy against inhibition of cattle tick breeding.

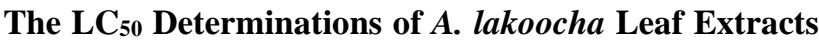 against $R$. (B.) microplus}

The lethal concentration fifty $\left(\mathrm{LC}_{50}\right), 95 \%$ confidence interval and slope were determined from the 24-hour counts using the Probit analysis method described by StatPlus program that shown in the graph of Fig. 3. The concentration of $A$. lakoocha extract $1600 \mu \mathrm{g} / \mathrm{ml}$ had $\mathrm{LC}_{50}$ as $1050 \mu \mathrm{g} / \mathrm{ml}$ that could provide tick mortality rate at $50 \%$.

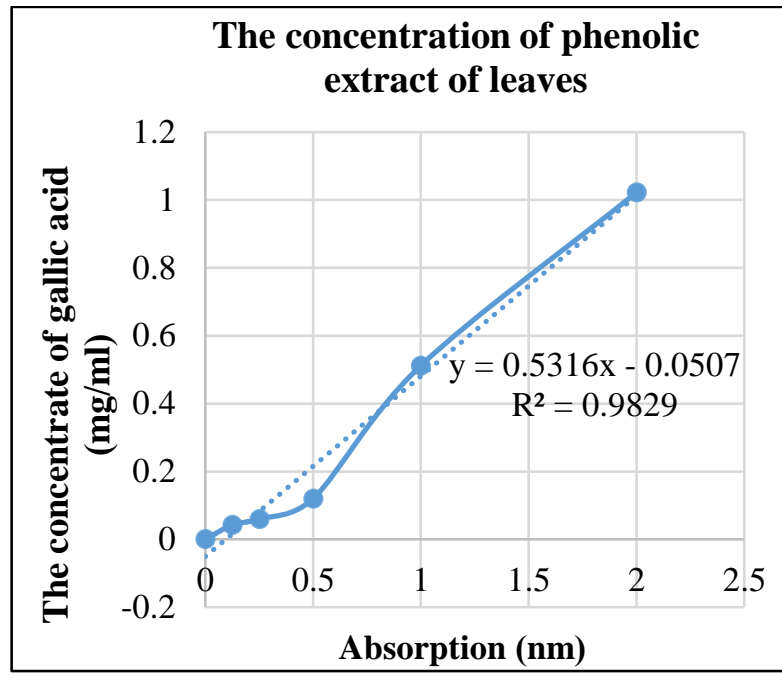

Fig. 1: The standard curve of phenolic compound. From this graph the equation obtained from the analysis is $y=0.5316$ 0.0507. Equation 1. $\mathrm{R}^{2}$ value $=0.9829$ which is the value represents the relationship between $\mathrm{X}$-axis and $\mathrm{Y}$-axis: $\mathrm{X}$-axis is standard concentration of gallic acid $(\mathrm{mg} / \mathrm{ml})$ : Y-axis is absorption value with UV-vis-spectrophotometer at $765 \mathrm{~nm}$ light absorption.

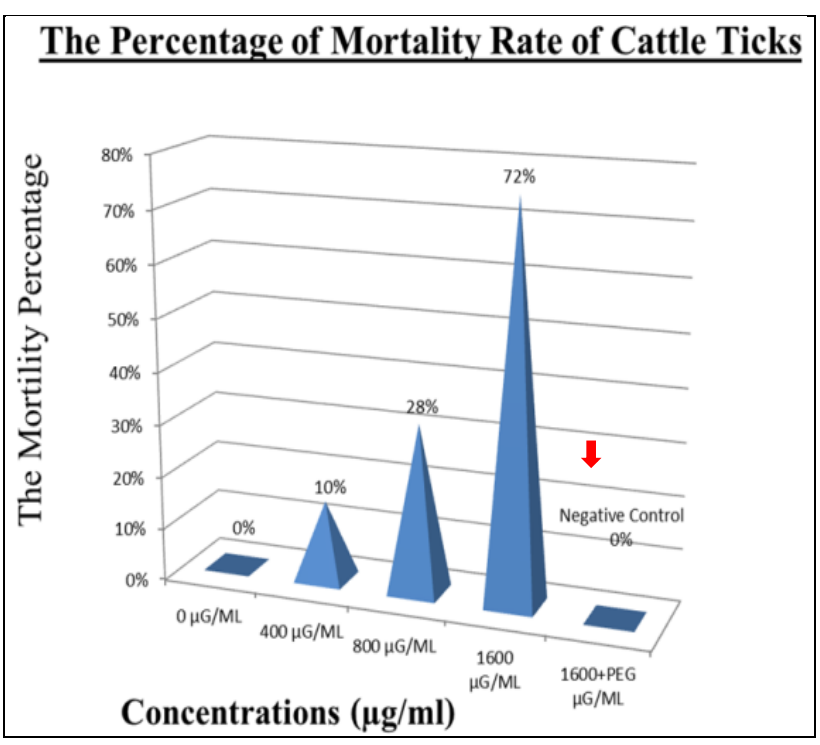

Fig. 2: The mortality percentage of cattle ticks in each concentration of phenolic extracts.

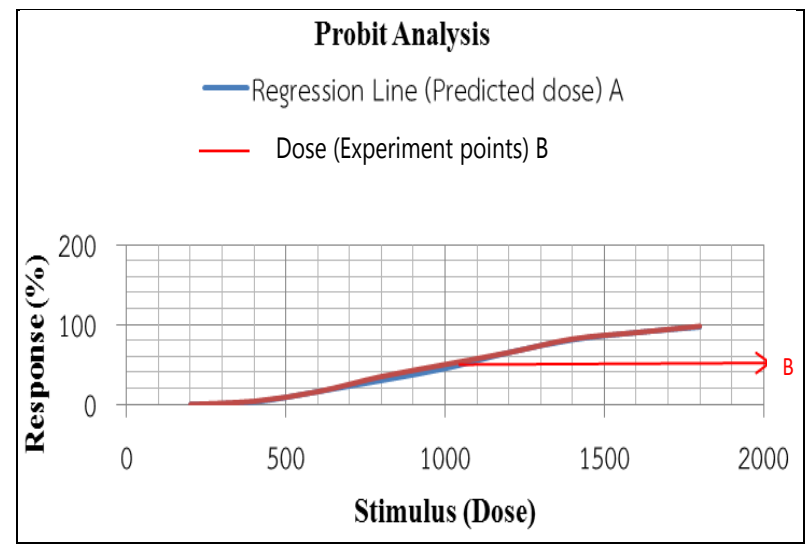

Fig. 3: The lethal concentrations of $1600 \mu \mathrm{g} / \mathrm{ml}$ crude extract from A. Lakoocha leaves. 
Table 1: The concentration of phenolic crude extract from $A$. lakoocha leaves

\begin{tabular}{lc}
\hline Substitution in equation & $\begin{array}{c}\text { Crude extract from } A . \\
\text { lacucha leaves }(\mathrm{mg} / \mathrm{ml})\end{array}$ \\
\hline Absorption (y) & 0.24 \\
Concentration of phenolic extract (X) & 0.54
\end{tabular}

Table 2: Efficacy of phenolic from A. lakoocha leaves to show as index of egg laying and inhibition fecundity index

\begin{tabular}{lcll}
\hline Concentration $(\mu \mathrm{g} / \mathrm{ml})$ & Body weight $/$ Repeat $(\mathrm{g})$ & $\mathrm{IE}$ & $\mathrm{IF}$ \\
\hline Control group & $0.1286 \pm 0.0558^{\mathrm{a}}$ & $0.22^{\mathrm{a}}$ & - \\
400 & $0.0968 \pm 0.0024^{\mathrm{a}}$ & $0.18^{\mathrm{a}}$ & $28.14^{\mathrm{a}}$ \\
800 & $0.1012 \pm 0.0414^{\mathrm{ab}}$ & $0.17^{\mathrm{a}}$ & $32.18^{\mathrm{a}}$ \\
1600 & $0.0714 \pm 0.0036^{\mathrm{b}}$ & $0.14^{\mathrm{b}}$ & $49.00^{\mathrm{b}}$
\end{tabular}

$\mathrm{a}, \mathrm{b}=95 \% \mathrm{CI}(\mathrm{P}<0.05), \mathrm{IE}=$ Index of egg laying, $\mathrm{IF}=$ Inhibition of fecundity.

\section{DISCUSSION}

The acaricidal effect of A. lakoocha leaves is resulted from tannin in leaf layer. According to previous studies, the efficiency of plant extracts is considered as the alternative treatment to arthropod control because they are a rich source of the secondary metabolites with active acaricidal activity, including terpenes, stilbenes, coumarins, acids, alcohols, sulfide compounds, tannins and aldehydes from essential oils (Fernández-Salas et al. 2011; Rosado-Aguilar et al. 2017). They present different action mechanisms in controlling ticks such as inhibition of feeding and chitin synthesis, decreased growth, development and reproduction and behavioral alterations; without adverse effects to non-target species (ArceoMedina et al. 2016).

The experimental results revealed that all concentrations of A. lakoocha leaf extracts had higher effect on the mortality of ticks than the control group, and also the highest mortality rate of cattle ticks was $72 \%$ with the concentration of $1600 \mu \mathrm{g} / \mathrm{ml}$. This indicates that if $A$. lakoocha leaf extracts were used properly, their botanical acaricide could be effective in controlling cattle ticks, which will be one of the eco-friendly ways for the organic cattle farming systems.

This research is an initial study of A. lakoocha leaf extract against cattle tick, the results suggested that the extract was effective to get rid of cattle ticks; however, the more toxicity of the extract has not been studied. Some types may be harmful to death if high quantity of them were applied or misused. The toxins in plants often contain alkaloid, some types of alkaloid are not toxic, but some types are very toxic. Plants play an important role in the prevention of insect pests due to the presence of the active alkaloids, which is related to the findings on the study of acaricidal activity of secondary metabolites from crude extract plants (Vernonia amygdalina, Calpurnia aurea, Schinus molle, Ricinus communis, Croton macrostachyus, and Nicotiana tabacum) against $R$. decoloratus and $R$. pulchellus in an in vitro adult immersion test with crude extract plants Quadros et al. (2020). Additionally, Islam et al. (2018) reported that ethanolic extracts from Magonia pubescens St. Hil (Sapindaceae) revealed no significant differences in larvicidal activity (90-100\%) against B. microplus. In our study, phenolic extracts were found to have comparatively less efficacy than methanolic extracts $(72 \%$ death in 48 hrs with $1600 \mu \mathrm{g} / \mathrm{ml}$ ). The $90 \%$ tick mortality was recorded in 3\% aqueous extract concentration after 36 hours interval; it could be the best cost-effective alternative. A study carried out by Nyahangare et al. (2019) showed that the treatment of aqueous neem seed oil extracts at concentration level of $1.6 \%$ and $3.2 \%$ were against eggs, nymphs and adult stages of Hanatolicum excavatum, suggesting that these two acaricide concentration levels could be applied for the effective control of cattle ticks.

Notably, PEG was considered as a negative control group for verifying the efficacy of phenolic compound of A. lakoocha leaf extracts in eliminating cattle tick because this chemical has ability to easily bind to the phenolic compounds that present in A. lakoocha leaf extracts. As a result, the bound phenolic compounds are unable to remove the entire ticks (Makkar 2003). Experimentally, we found that when PEG was added to A. lakoocha leaf extracts, the mortality percentage was equal to 0 . This finding indicates that the phenolic compound is the main bioactive compound in A. lakoocha leaf extracts, which had effect on the mortality of cattle ticks.

At present, Probit system has been applied in the analysis by calculating Lethal Concentration 50 ( $\left.\mathrm{LC}_{50}\right)$ because it is precisely method and accurate. $\mathrm{LC}_{50}$ value means the concentration of the toxin that caused the death of the experimental animals in the specified period. However, if $\mathrm{LC}_{50}$ value has high numeric value, such substances will have less danger. Due to receiving large quantity, the experimental animals would be dead as half of tested animal group While low numerical values indicate highly severe toxicity, it means receiving of little amount would cause mortality of half of tested animals. Our results showed that $\mathrm{LC}_{50}$ value was equal to 1050 $\mu \mathrm{g} / \mathrm{ml}$ that could provide tick mortality rate at $50 \%$. However, the toxicity of A. lakoocha leaves to animals and humans has not been observed in this study.

Thus, leaves are the important sources of bioactive compound, which could be used as a potent natural acaricide against tick instead of the synthetic chemical acaricides. Our findings could serve as alternative, environmentally friendly tick control strategies with lower chance of the development of resistance. Importantly, further studies of the extract activity and their potential as tick control agents, including extraction and effective preparation should be conducted to apply in medical and veterinary fields in the future. However, further research is needed to identify the chemical structures of crude extract compounds of leaf extracts from A. lakoocha, responsible for getting rid of cattle ticks, since the obtained crude phenolic extracts could serve as a great promise for utilized as biocidal active substance against pests and diseases that afflict plants and animals, including humans. Phytochemicals generally are regarded as research compounds because these approaches can proof biological activity in the products of metabolism of plants. Furthermore, phytochemical research has applications in the pharmaceutical industry, including organic cattle farming Braga et al. (2018).

\section{Conclusion}

The A. lakoocha leaf extract at the concentration of $1600 \mu \mathrm{g} / \mathrm{ml}$ had the most effectiveness against mortality rate, index of egg laying and percentage of tick breeding 
inhibition at $72 \%, 0.14$ and $49 \%$, respectively, compared with the control group and other concentrations. In addition, the $\mathrm{LC}_{50}$ value of $A$. lakoocha leaf extract was equal to $1050 \mu \mathrm{g} / \mathrm{ml}$.

\section{Acknowledgement}

I would like to thank the scholar supports from Plant Conservation Project Under the Royal Initiation of Her Royal Highness Princess Maha Chakri Sirindhorn (RSPG) 2020, Department of Veterinary Technology, Faculty of Agricultural Technology, Kalasin University for providing laboratory support and Asist Prof. Fanan Suksawat for scientific guidance.

\section{Author's Contribution}

S. Wilasinee designed the study, collected in samples collection, identified ticks, performing the test, Manuscript writing and data analysis. B. Dechawut identified A. lakoocha leaves, manuscript writing. All authors drafted and revised the manuscript as well as read and approved the final manuscript.

\section{REFERENCES}

Abbott WS, 1925. A method of computing the effectiveness of an insecticide. Journal of Economic Entomology 23: 265267. https://doi.org/10.1093/jee/18.2.265a

Adenubi OT, Fasina F, McGaw L, Eloff J and Naidoo V, 2016. Plant extracts to control ticks of veterinary and medical importance: A review. South African Journal of Botany 105: 178-193. https://doi.org/10.1016/j.sajb.2016.03.010

Adakal H, Stachurski F and Chevillon C, 2013. Tick control practices in Burkina Faso and acaricide resistance survey in Rhipicephalus (Boophilus) geigyi (Acari: Ixodidae). Experimental and Applied Acarology 59: 483-491. https://doi.org/10.1007/s10493-012-9610-5

Arceo-Medina GN, Rosado-Aguilar JA, Rodríguez-Vivas RI and Borges-Argaez R, 2016. Synergistic and antagonistic action of fatty acids: sulphides and stilbene against acaricideresistant Rhipicephalus microplus ticks. Veterinary Parasitology 228: 121-125. https://doi.org/10.1016/j.vetpar. 2016.08.023

Braga AGS, de Souza KFA, da Silva Barbieri FS, de Freitas Fernandes C, Rocha RB, Vieira Junior JR, Lacerda CL, Celestino CO, Facundo VA and Brito LG, 2018. Acaricidal activity of extracts from different structures of Piper tuberculatum against larvae and adults of Rhipicephalus microplus. Acta Amazonica 48: 57-62. https://dx.doi.org/ 10.1590/1809-4392201700053

Castro KN, Lima DF, Vasconcelos LC, Leite JR, Santos RC, Paz Neto AA and Costa-Junior LM, 2014. Acaricide activity in vitro of Acmella oleracea against Rhipicephalus microplus. Parasitology Research 113: 3697-3701. https://doi.org/10.1007/s00436-014-4034-2

Chungsamarnyart N, Jiwajinda S, Rattanakreetakul C and Jansawan W, 1992. Acaricidal effect of practical crude extract of plants against tropical cattle ticks. Kasetsart Journal (Natural Sciences) 27: 57-64.

de Castro JJ, 1997. Sustainable tick and tickborne disease control in livestock improvement in developing countries. Veterinary Parasitology 71: 77-97. https://doi.org/10.1016/ S0304-4017(97)00033-2

Diaz GJ, 2015. Toxicosis by Plant Alkaloids in Humans and Animals in Colombia. Toxins 7: 5408-5416. https://doi.org/10.3390/toxins7124892

Fernández-Salas A, Alonso-Díaz MA, Acosta-Rodríguez R, Torres-Acosta FJ, Sandoval-Castro CA and RodríguezVivas RI, 2011. In vitro Acaricidal effect of tannin-rich plants against the cattle tick Rhipicephalus (Boophilus) microplus (Acari: Ixodidae). Veterinary Parasitology 175:113-118. https://doi.org/10.1016/j.vetpar.2010.09.016

Greeshma UB, Narladkar B and Rajurkar S, 2018. In-vitro evaluation of the herbal acaricide product against the cattle tick Rhipicephalus (B.) microplus (Acarina ixodidiae). Journal of Entomology and Zoology Studies 6: 544-548.

Islam S, Talukder S, Ferdous J, Hasan MM, Sarker YA, Sachi S, Alim MA and Sikder MH, 2018. In-vitro efficacy of verenda (Ricinus communis) leaves extract against ticks in cattle. Bangladesh Journal of Veterinary Medicine 16: 8186. https://doi.org/10.3329/bjvm.v16i1.37380

Kemal J, Zerihun T, Alemu S, Sali K, Nasir M, Abraha A and Feyera T, 2020. In Vitro Acaricidal Activity of Selected Medicinal Plants Traditionally Used against Ticks in Eastern Ethiopia. Journal of Parasitology Research 2020: 7834026 https://doi.org/10.1155/2020/7834026

Makkar HPS, 2003. Measurement of Total Phenolics and Tannins Using Folin-Ciocalteu Method. Quantification of Tannins in Tree and Shrub Foliage. Springer, Dordrecht, pp 49-51. https://doi.org/10.1007/978-94-017-0273-7_3

Marchesini P, Barbosa AF, Franco C, Novato T, Sanches MNG, de Carvalho MG, Fabri RL, Daemon E and Monteiro CMO, 2018. Activity of the extract of Acmella oleracea on immature stages of Amblyomma sculptum (Acari: Ixodidae). Veterinary Parasitology 254: 147-150. https://doi.org/10.1016/j.vetpar.2018.03.009

Morais-Urano RP, Chagas ACS and Berlinck RGS, 2012. Acaricidal action of destruxins produced by a marinederived Beauveria felina on the bovine tick Rhipicephalus (Boophilus) microplus, Experimental Parasitology 132: 362-366. https://doi.org/10.1016/j.exppara.2012.08.011

Nesa ML, Munira S, Bristy AS, Islam MM, Chayan H and Rashid M, 2015. Cytotoxic, anti-inflammatory, analgesic, CNS depressant, antidiarrhoeal activities of the methanolic extract of the Artocarpus lakoocha leaves. World Journal of Pharmaceutical Sciences 3: 167-174.

Nyahangare ET, Mvumi BM, McGaw LJ and Eloff JN, 2019. Addition of a surfactant to water increases the acaricidal activity of extracts of some plant species used to control ticks by Zimbabwean smallholder farmers. BMC veterinary research 15: 404. https://doi.org/10.1186/s12917-019-2078-3

Ponce-Vélez G and de la Lanza-Espino G, 2019. Organophosphate Pesticides in Coastal Lagoon of the Gulf of Mexico, Journal of Environmental Protection 10: 103117. https://doi.org/10.4236/jep.2019.102007

Quadros DG, Johnson TL, Whitney TR, Oliver JD and Oliva Chávez AS, 2020. Plant-derived natural compounds for tick pest control in livestock and wildlife: pragmatism or utopia? Insects 11: 490. https://doi.org/10.3390/insects $\underline{11080490}$

Rosado-Aguilar JA, Arjona-Cambranes K, Torres-Acosta JFJ, Rodríguez-Vivas RI, Bolio-González ME and OrtegaPacheco A, 2017. Plant products and secondary metabolites with acaricide activity against ticks. Veterinary Parasitology 138: 66-76. https://doi.org/10.1016/j.vetpar. $\underline{2017.03 .023}$

Santos-Buelga C, Gonzalez-Manzano S, Dueñas $M$ and Gonzalez-Paramas AM, 2012. Extraction and Isolation of Phenolic Compounds. Natural Products Isolation, part of the Methods in Molecular Biology (Methods and Protocols), vol 864. Humana Press, pp: 427-464. https://doi.org/10.1007/978-1-61779-624-1_17

Slinkard K and Singleton VL, 1997. Total phenol analysis: automation and comparison with many methods. American Journal of Enology and Viticulture 28: 49-55.

Veeramani V, Sakthivelkumar S, Tamilarasan K, Aisha SO and Janarthanan S, 2014. Acaricidal activity of Ocimum basilicum and Spilanthes acmella against the ectoparasitic tick, Rhipicephalus (Boophilus) microplus (Arachinida: Ixodidae). Tropical Biomedicine 31: 414-421. 